\title{
Cytogenetic Analysis of Micronuclei in Tobacco Chewers: A Study in North Indian Population
}

\author{
Neha Vaid ${ }^{1}$, Deepak Bhargava ${ }^{2}$, Puja Bansal ${ }^{3}$, Rajeshwar Chawla $^{4}$, Deepak Goyal ${ }^{5}$, Chander US Pawar $^{6}$
}

\begin{abstract}
Aim: Oral cancer ranks in top three of all cancers in India and accounts for over $30 \%$ of all cancers reported in the country. The present study aims at an in vivo cytogenetic analysis to assess the applicability of the micronucleus test in diagnosing early detection of dysplastic changes. Materials and methods: Exfoliated scrape smears were collected from 75 patients suffering from premalignant lesions. The wet-fixed smears were stained by adopting Papanicolaou's staining protocol. The analysis of variance (ANOVA) test was used to analyze the data statistically.

Results: The results of the above study give a fair assessment of the amount of nuclear alterations seen in individuals exposed to genotoxic agents, such as tobacco, and also to a certain extent, an insight into the expected biological behavior of the lesions present in such individuals. Detection of micronuclei and their assay is an upcoming research domain in the field of cancer detection and therapeutics. These miniature nuclear offshoots if properly identified can turn out to be important biomarkers with huge potential for screening and predicting patients with oral precancers and also can act as risk assessors in patient's ongoing treatment for invasive cancers.

Conclusion: The frequency of micronucleated cells has been observed to be in increasing order with the increase in the age-groups and from control to precancerous cases significantly in both sexes.
\end{abstract}

Keywords: Biomarker, Micronuclei, Tobacco chewers.

The Journal of Contemporary Dental Practice (2019): 10.5005/jp-journals-10024-2581

\section{INTRODUCTION}

Cancer may be a malady of genes, arising from genetic damage. ${ }^{1}$ Oral cancer is one of the 10 most common cancers in the World ${ }^{2}$ and is a complex disease with altered expression, abnormal growth, and disruption of normal function of cells caused by the genotoxic effects of chemical carcinogens. ${ }^{3}$ The lifestyle factors that are associated with genetic damage include smoking, alcohol consumption, and tobacco consumption. ${ }^{4}$ In Asia-Pacific region, betel quid habit is one of the main causative agents of potentially malignant disorders. The $\mathrm{N}$-nitrosamine present in tobacco content of betel quid is clastogenic and mutagenic in nature. This causes chromosomal aberration and induces formation of micronuclei in oral epithelial cells. ${ }^{5}$

Micronuclei (MN) are small chromatin bodies in the cytoplasm formed by condensation of acrocentric chromosomal fragments or by whole chromosomes, lagging behind the cell division and are sensitive indicators of genetic damage. It is the only biomarker that allows simultaneous evaluation of clastogenic and aneugenic effects in multiple cells, easily detected in the interphase. ${ }^{3}$ Assessment of the number of MN may be used as a strategy to identify the genotoxic damage in epithelial cells, which are exposed to carcinogens or mutagens. An increase in the number of MN in exfoliated cells indicates an increased risk for cancer. ${ }^{6}$

Investigations on MN frequencies support the widely accepted assumption that MN are a product of early events in human carcinogenesis processes. A number of laboratories from different countries either have used, or are currently using micronucleus assay for the early detection of cancer. ${ }^{2}$

So, the present study aims to determine the specificity and sensitivity of the micronucleus assay in tobacco chewers for detecting dysplastic changes and to compare micronuclei frequency in tobacco chewers and healthy nontobacco chewers.

\footnotetext{
1,4-6Jan Nayak Ch. Devi Lal Dental College, Sirsa, Haryana, India

${ }^{2,3}$ School of Dental Sciences, Sharda University, Greater Noida, Uttar Pradesh, India
}

Corresponding Author: Neha Vaid, Jan Nayak Ch. Devi Lal Dental College, Sirsa, Haryana, India, Phone: +91 8685915272, e-mail: dr.nehavaid@gmail.com

How to cite this article: Vaid N, Bhargava D, et al. Cytogenetic Analysis of Micronuclei in Tobacco Chewers: A Study in North Indian Population. J Contemp Dent Pract 2019;20(6):693-696.

Source of support: Nil

Conflict of interest: None

\section{Subjects and Methods}

A total of 75 patients divided into three groups, i.e., patients having the habit of tobacco chewing without lesion and patients having the habit of tobacco chewing with premalignant lesions like leukoplakia, erythroplakia, tobacco pouch keratosis, and healthy control, who visited the Department of Oral and Maxillofacial Pathology, School of Dental Sciences, Sharda University, Greater Noida (India), were included in the study. Participants of all the age groups ranging from $10-55$ years and above irrespective of their sex were included in this study. Detailed anamnesis depicting habits was noted down along with informed consent form. Individuals who had a recent viral infection or had undergone radiation therapy and who were under medication were excluded from the study. Criteria for the total cell count were as suggested by Tolbert et al. ${ }^{7}$ and criteria parameters for identifying micronucleus are as follows:

- Rounded smooth perimeter suggestive of a membrane.

- Less than one-third the diameter of the associated nucleus, but large enough to discern shape and color.

() The Author(s). 2019 Open Access This article is distributed under the terms of the Creative Commons Attribution 4.0 International License (https://creativecommons. org/licenses/by-nc/4.0/), which permits unrestricted use, distribution, and non-commercial reproduction in any medium, provided you give appropriate credit to the original author(s) and the source, provide a link to the Creative Commons license, and indicate if changes were made. The Creative Commons Public Domain Dedication waiver (http://creativecommons.org/publicdomain/zero/1.0/) applies to the data made available in this article, unless otherwise stated. 
- Staining intensity similar to the nucleus.

- Texture similar to the nucleus.

- Same focal plane as the nucleus.

- Absence of overlap with or bridge to the nucleus.

Dead or degenerating cells (karyolysis, karyorrhexis, and nuclear fragmentation) were excluded from evaluation. Nuclear blebbings (micronucleus-like structure connected with the main nucleus with a bridge) were also not considered.

Scraping of the oral mucosa made with a sterilized wooden tongue depressor was smeared onto pre-cleaned microscopic slides. Smears were air-dried and fixed in $80 \%$ methanol within 24 hours. Staining with Papanicolaou stain was done and at least 100 exfoliated epithelial cells were observed and evaluated under $100 \times$ view of a light microscope. Three evaluators evaluated and verified the results. The criteria for identifying micronuclei as given by Tolbert et al. ${ }^{7}$ were followed. Findings of the present study were statistically analyzed and comparisons between different groups in relation to micronuclei frequency and presence of total number of cells with micronuclei using ANOVA were made. Ethical committee's approval was taken from the institute.

\section{Results}

\section{Clinical Observations}

\section{Age Distribution}

In group-l out of 25 patients, 1 was in the age group of 10-20 years, 12 were in the age group of 21-30 years, 8 were in the age group of 31-40 years, 2 were in the age group of $41-50$ years, and 2 were in the age group of 51 years and above. So, the maximum number of the cases in group-l, i.e. 12, was within the age range of 21-30 years (Table 1).

In group-II out of 25 patients, 1 was in the age group of 10-20years, 8 were in the age group of 21-30 years, 7 were in the age group of $31-40,7$ were in the age group of 41-50 years, and 2 were in the age group of 51 years and above, respectively. So, the maximum number of the cases in group-II, i.e. 18, was within the age range of 21-30 years.

In group-III out of 25 patients, 1 was in the age group of $10-20$ years, 10 were in the age group of 21-30 years, 6 were in the age group of 31-40 years, 5 were in the age group of 41-50 years, and 3 were in the age group of 51 years and above, respectively. So, the maximum number of the cases in group-III, i.e. 10, was within the age range of 21-30 years.

The mean age of individuals in group-I was 37.16 with a standard deviation of 10.33. In group-II, the mean age of individuals was 37.84 with a standard deviation of 11.175 , and in group-III, the mean age was 35.84 with a standard deviation of 13.66 .

\section{Sex Distribution}

A total of 75 patients comprised of 63 males and 12 females. Group-I comprised of 25 males, group-II comprised of 24 males and 1 female, and group-III comprised of 14 males and 11 females.

Table 1: Age distribution in the study groups

\begin{tabular}{lccc}
\hline Age (years) & Group-I & Group-II & Group-III \\
\hline $10-20$ & 1 & 1 & 1 \\
$21-30$ & 12 & 8 & 10 \\
$31-40$ & 8 & 7 & 6 \\
$41-50$ & 2 & 7 & 5 \\
51 and above & 2 & 2 & 3 \\
Total & 25 & 25 & 25 \\
\hline
\end{tabular}

Table 2: Duration of tobacco chewing in group I and group II

\begin{tabular}{lcl}
\hline Duration (years) & Group I & Group II \\
\hline $0-5$ (years) & 8 & 4 \\
$6-10$ (years) & 11 & 7 \\
$11-15$ (years) & 2 & 9 \\
$16-20$ (years) & 2 & 5 \\
21 and above (years) & 0 & 1 \\
\hline
\end{tabular}

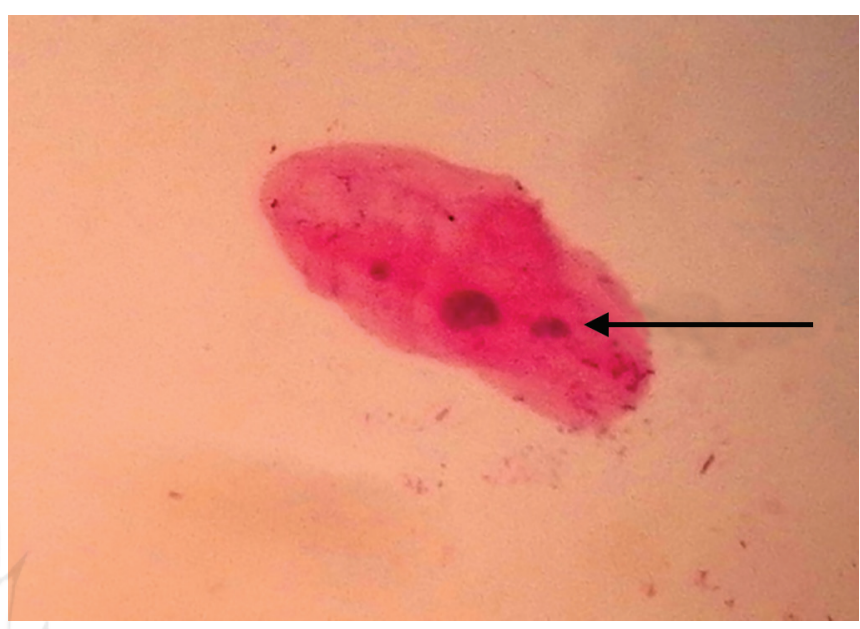

Fig. 1: Papanicolaou stain (PAP) stained cytological smear showing micronuclei at $100 \times$ magnification

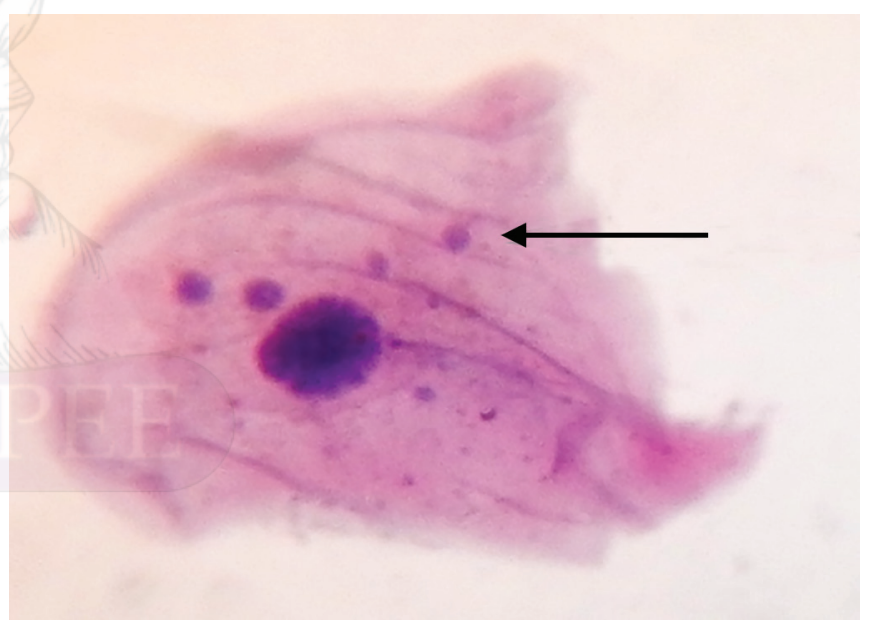

Fig. 2: PAP stained cytological smear showing micronuclei at $100 \times$ magnification

\section{Duration of Tobacco Chewing}

The duration of tobacco chewing in $0-5$ years in group I was 8 and in group II was 4. The duration of tobacco chewing in 6-10 years in group I was 11 and in group II was 4 . The duration of tobacco chewing in 11-15 years in group I was 2 and in group II was 9 . The duration of tobacco chewing in 16-20 years in group I was 2 and in group II was 5 . The duration of tobacco chewing in 21 years and above in group I was 0 and in group II was 1 (Table 2).

Comparison of micronuclei (Figs 1 and 2) in group-l and groupIII was done with ANOVA and mean \pm SD in group-I and group-III were $37.16 \pm 4.279$ and $12.64 \pm 2.481$. The mean \pm SD in total number 
Cytogenetic Analysis of Micronuclei

Table 3: Comparison of the mean micronuclei frequency and total number of cells with micronuclei in groups I and III

\begin{tabular}{|c|c|c|c|c|c|}
\hline \multirow[b]{2}{*}{ Parameters } & \multirow{2}{*}{$\begin{array}{l}\text { Group I } \\
\text { Mean } \pm S D\end{array}$} & \multirow{2}{*}{$\begin{array}{l}\text { Group III } \\
\text { Mean } \pm S D\end{array}$} & \multicolumn{3}{|c|}{ Comparison of GI/GIII } \\
\hline & & & t value & $p$ value & Statistically significant \\
\hline Number of micronuclei & $37.16 \pm 4.279$ & $12.64 \pm 2.481$ & 24.828 & $<0.0001$ & $\mathrm{HS}$ \\
\hline Total number of cells with micronuclei & $19.44 \pm 6.820$ & $7.16 \pm 2.230$ & 8.55 & $<0.0001$ & HS \\
\hline
\end{tabular}

HS, highly significant

Table 4: Comparison of the mean micronuclei frequency and total number of cells with micronuclei in groups I and group II

\begin{tabular}{|c|c|c|c|c|c|}
\hline \multirow[b]{2}{*}{ Parameters } & \multirow{2}{*}{$\begin{array}{l}\text { Group I } \\
\text { Mean } \pm S D\end{array}$} & \multirow{2}{*}{$\begin{array}{l}\text { Group II } \\
\text { Mean } \pm S D\end{array}$} & \multicolumn{3}{|c|}{ Comparison of GI/GII } \\
\hline & & & tvalue & $p$ value & Statistically significant \\
\hline Number of micronuclei & $37.16 \pm 4.279$ & $87.48 \pm 14.460$ & 16.68 & $<0.0001$ & $\mathrm{HS}$ \\
\hline Total number of cells with micronuclei & $19.44 \pm 6.820$ & $25.32 \pm 10.221$ & 2.39 & $<0.020$ & $\mathrm{~S}$ \\
\hline
\end{tabular}

Table 5: Comparison of the mean micronuclei frequency and total number of cells with micronuclei in groups II and group III

\begin{tabular}{|c|c|c|c|c|c|}
\hline \multirow[b]{2}{*}{ Parameters } & \multirow{2}{*}{$\begin{array}{l}\text { Group II } \\
\text { Mean } \pm S D\end{array}$} & \multirow{2}{*}{$\begin{array}{l}\text { Group III } \\
\text { Mean } \pm S D\end{array}$} & \multicolumn{3}{|c|}{ Comparison of GII/GIII } \\
\hline & & & tvalue & $p$ value & Statistically significant \\
\hline Number of micronuclei & $87.48 \pm 14.460$ & $12.64 \pm 2.481$ & 25.505 & $<0.0001$ & HS \\
\hline Total number of cells with micronuclei & $25.32 \pm 10.221$ & $7.16 \pm 2.230$ & 8.679 & $<0.0001$ & HS \\
\hline
\end{tabular}

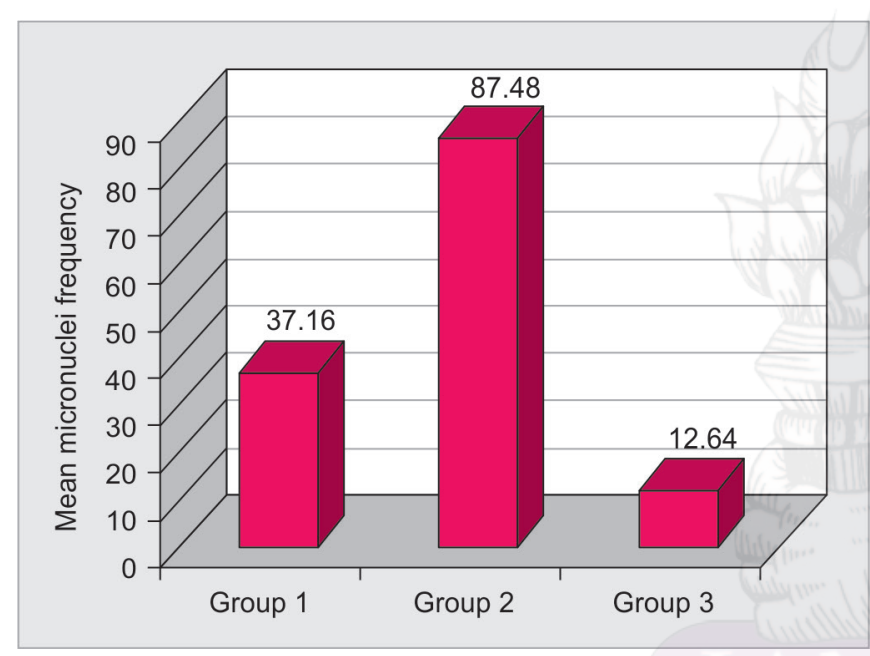

Fig. 3: Comparative mean micronuclei frequency among three groups

of cells with micronuclei in group-I and group-III was $19.44 \pm 6.820$ and $7.16 \pm 2.230$ (Table 3).

Comparison of micronuclei in group I and group II showed that mean \pm SD in group 1 and group 2 was $37.16 \pm 4.279$ and $87.48 \pm$ 14.460. The mean \pm SD in the total number of cells with micronuclei in group I and group II was $19.44 \pm 6.820$ and $7.16 \pm 2.230$ (Table 4).

Comparison of micronuclei in group II and group III showed that mean \pm SD in group 2 and group 3 was $87.48 \pm 14.460$ and $12.64 \pm 2.481$. The mean \pm SD in the total number of cells with micronuclei in group II and group III was $25.32 \pm 10.221$ and $7.16 \pm 2.230$ (Table 5).

It was observed that there was statistically significant difference between the control group, tobacco chewers, and tobacco chewers with lesion. The $p$ value was found to be statistically significant among all the three groups (Fig. 3).

\section{Discussion}

Lung, oropharyngeal, and oral cavity cancers are the most common cancer sites observed by Indian registries. These cancer sites are causally related to the use of tobacco in different forms. In India, the use of tobacco is common in the form of chewing and smoking of beedis and cigarettes. ${ }^{8}$

In the present study, making use of exfoliated buccal cells for assaying MN can be arguably explained based on two reasons. First, since approximately $90 \%$ of human cancers originate from epithelial cells, they represent a preferred target site for early genotoxic events induced by carcinogenic agents entering the body by way of inhalation and ingestion. The second reason is that the collection of buccal cells is certainly the least invasive method available for measuring the DNA damage in humans. ${ }^{9}$ The method of counting of $\mathrm{MN}$ also needs to be modified. Consequently, we intend to put forward a modified formula as done by Jadhav et al. ${ }^{10}$ as follows:

Average frequency of $\mathrm{MN}=$ total number of $\mathrm{MN} /$ total number of cells with $\mathrm{MN} .^{10}$

The present study showed no association between the age and the occurrence of micronucleus. It is in agreement with the study done by Uma et al. ${ }^{8}$ However, the study conducted by Caplash et al. ${ }^{11}$ had shown that the frequency of the micronucleus increases with age.

It was also observed in the present study that a sizable amount of group-I, group-II, and group-III cases was males when compared to a very small percent of cases being females. This disparity in the sex distribution could be due to a semi-urban cultural, social, and educational background of our subjects in the study group. The female subjects consuming tobacco in the study group were observed to be from a lower socioeconomic background. In a study conducted by Subramanian et al. ${ }^{12}$ on patterns and distribution of tobacco consumption in India, it was observed that men smoked and chewed tobacco considerably more than women.

The duration of addiction of the chewing habit in the present study of 50 individuals was in average of 1-20 years, which is in accordance with the study done by Jyoti et al. ${ }^{13}$

In present study, the tobacco chewers and betel quid chewers have shown a greater number of $\mathrm{MN}$ as compared to the healthy control group. This finding relates to that of Sellappa et al., ${ }^{14}$ Palaskar and Jindal, ${ }^{15}$ Joshi et al., ${ }^{16}$ Dosi et al., ${ }^{17}$ and Sharma et al. ${ }^{4}$ We also observed variations in the frequency of micronucleated cells in the control group, which may be probably due to the different food habits within the population group as individuals are exposed to 
various chemicals in their daily life, which was the reason for the variable levels of micronucleated cells. ${ }^{13}$

On the other hand, Bansal et al. ${ }^{18}$ and Ozkul et al. ${ }^{19}$ in their work showed a higher level of the mean number of $\mathrm{MN}$ in smokeless tobacco users as compared with smokers, thus indicating higher carcinogenic potential of smokeless tobacco.

There is a three-fold higher MN rate per cell in the group of tobacco chewers and tobacco chewers with lesion patients than in the control group, and a number of studies have shown a gradual increase in $\mathrm{MN}$ frequency from normal to precancerous to cancerous lesions as done by Palaskar and Jindal, ${ }^{15}$ Jyoti et al., ${ }^{13}$ Caplash et al., ${ }^{11}$ and Dosi et al. ${ }^{17}$

Cytobrushes appear to be most effective for collecting large numbers of cells, and the high expense makes them less feasible for routine purposes. So, we preferred the use of a wooden spatula.

The present study followed the Papanicolaou technique for staining purpose as suggested by Palaskar and Jindal, ${ }^{15}$ and Somashekhar and Kamath ${ }^{5}$ since it is very simple to use, less time consuming, and economical. Moreover, the present study demonstrated that the buccal cell MN assay is a cost-effective, sensitive, and accurate procedure, which can be easily carried out for population-based studies as suggested by Sellappa et al. ${ }^{14}$

The present study demonstrates that the frequency of micronuclei was significantly higher in individuals with lesions and without lesions who were having tobacco habits than in controls who were not having tobacco habits. The control group showed a minimal number of micronuclei when compared to the studied individuals. So, it affirms that tobacco in any form has genotoxic and cytotoxic potential that induces the formation of micronuclei in the oral epithelium, making it more prone to develop potentially malignant and squamous cell carcinoma.

The results of the above study give a fair assessment of the amount of nuclear alterations seen in individuals exposed to genotoxic agents, such as tobacco, and also to a certain extent, an insight into the expected biological behavior of the lesions present in such individuals. Detection of micronuclei and their assay is an upcoming research domain in the field of cancer prevention and therapeutics. These miniature nuclear offshoots if properly identified can turn out to be important biomarkers with huge potential for screening and predicting patients with oral precancers and also can act as risk assessors in patient's ongoing treatment for invasive cancers.

\section{Clinical Significance}

This study gives a fair assessment of the amount of nuclear alterations seen in individuals exposed to genotoxic agents, such as tobacco, and also to a certain extent, an insight into the expected biological behavior of the lesions present in such individuals.

\section{References}

1. Suhas S, Ganapathy KS, et al. Application of the micronucleus test to exfoliated epithelial cells from the oral cavity of beedi smokers, a high-risk group for oral cancer. Mutat Res 2004;561:15-21. DOI: 10.1016/j.mrgentox.2004.03.001.

2. Holland N, Bolognesi $C$, et al. The micronucleus assay in human buccal cells as a tool for biomonitering DNA damage: the HUMN project perspective on current status and knowledge gaps. Mutat Res 2008;659(1-2):93-108. DOI: 10.1016/j.mrrev.2008.03.007.

3. Motgi AA, Chavan MS, etal. Assessment of cytogenic damage in the form of micronuclei in oral epithelial cells in patients using smokeless and smoked form of tobacco and non-tobacco users and its relevance for oral cancer.J Cancer Res Ther 2014;10:165-170. DOI: 10.4103/0973-1482.131454.

4. Sharma S, Rai S, et al. Quantitative and qualitative analysis of micronuclei in the buccal mucosal cells of individuals associated with tobacco. MAMC J Med Sci 2018;4(1):12-17.

5. Somashekhar P, Kamath VV. Evaluation of micronuclei in betel quid chewers, potentially malignant oral disorders, and oral squamous cell carcinoma patients: a cytological assay. J Adv Clin Res Insights 2016;3(4):139-142.

6. Sagari SG, Babannavar R, et al. Micronuclei frequencies and nuclear abnormalities in oral exfoliated cells of nuclear power plant workers. J Clin Diagn Res 2014 Dec;8(12):ZC15-ZC17. DOI: 10.7860/ JCDR/2014/9059.5240.

7. Tolbert PE, Shy CM, et al. Micronuclei and other nuclear anomalies in buccal smears: A Reid test in snuff users. Am J Epidemiol 1991;134(8):840-850.

8. Uma AN, Dhananjay SK, et al. Comparative cytogenetic study of exfoliative oral mucosal cells in tobacco related potentially malignant disorders in a South Indian population. Int J Adv Res Technol 2014;3(8):6-12.

9. Schmid W. The micronucleus test. Mutat Res 1975;31(1):9-15.

10. Jadhav K, Gupta N, et al. Micronuclei: an essential biomarker in oral exfoliated cells for grading of oral squamous cell carcinoma. J Cytol 2011;28(1):7-12. DOI: 10.4103/0970-9371.76941.

11. Caplash S, Meenakshi, et al. Micronucleus investigation in exfoliated buccal cells among tobacco chewers/smokers and controls. IJBPAS January 2013;2(1):72-79.

12. Subramanian SV, Nandy S, et al. Patterns and distribution of tobacco consumption in India: cross sectional multilevel evidence from the 1998-1999 national family health survey. BMJ 2004;328:801-806. DOI: $10.1136 / \mathrm{bmj} .328 .7443 .801$.

13. Jyoti $\mathrm{S}$, Khan $\mathrm{S}$, et al. Micronucleus investigation in human buccal epithelial cells of gutkha users. Adv Biomed Res 2012;1(2):1-4.

14. Sellappa $\mathrm{S}$, Balakrishnan $\mathrm{M}$, et al. Induction of micronuclei in buccal mucosa on chewing a mixture of betel leaf, areca nut and tobacco. J Oral Sci 2009;51(2):289-292.

15. Palaskar S, Jindal C. Evaluation of micronuclei using Papanicolaou and May Grunwald Giemsa stain in individuals with different tobacco habits - A comparative study. J Clin Diagn Res 2010;4:3607-3613.

16. Joshi MS, Verma Y, et al. Cytogenetic alterations in buccal mucosa cells of chewers of areca nut and tobacco. Arch Oral Biol 2011;56:63-67. DOI: 10.1016/j.archoralbio.2010.08.012.

17. Dosi $T$, Gupta $D$, et al. Assessment of micronuclei frequency in individuals with a habit of tobacco by means of exfoliated oral buccal cells. J Int Soc Prev Community Dent 2016;6(2):S143-S147. DOI: 10.4103/2231-0762.189745.

18. Bansal H, Sandhu VS, et al. Evaluation of micronuclei in tobacco users: a study in Punjabi population. Contemp Clin Dent 2012;3(2):184-187. DOI: 10.4103/0976-237X.96825.

19. Ozkul Y, Donmez H, et al. Induction of micronuclei by smokeless tobacco on buccal mucosa cells of habitual users. Mutagenesis 1997;12(4):285-287. 